\title{
A preliminary evaluation of an integrated aquaculture-agriculture systems (tilapia and peppers) at mesocosm scale
}

\begin{abstract}
A preliminary assay was conducted to evaluate the feasibility of an integrated aquacultureagriculture production system. Tilapia (Oreochromis niloticus) was farmed in plastic tanks (500L), with and without bioflocs incorporated. The effluents were passed to PVC tubes for a hydroponic culture of jalapeño pepper (Capsicum annum). The final effluent was used to a fertigation culture of mini bell pepper (Capsicum annum). The production response of tilapia was little better in tanks with bioflocs. The jalapeño pepper had not a good performance in the hydroponics system. Contrarily, mini bell pepper showed a good performance. We concluded that this aquaculture-agriculture system could be efficient, but some adjustments need to be done.
\end{abstract}

Keywords: aquaculture, agriculture, hydroponics, tilapia, peppers
Volume 9 Issue I - 2020

\author{
Luis Rafael Martinez-Cordova,' Jesus López- \\ Elías, ${ }^{2}$ Marcel Martinez-Porchas, ${ }^{4}$ Brando \\ Bringas Burgos, ${ }^{3}$ Jose Naranjo-Paramo' \\ 'DICTUS, Universidad de Sonora, Mexico \\ 2DAG, Universidad de Sonora, Mexico \\ ${ }^{3}$ Postgrado en Biociencias Universidad de Sonora, Mexico \\ ${ }^{4} \mathrm{CIAD}$, Mexico
}

Correspondence: Luis Rafael Martinez-Cordova, Universidad de Sonora, Blvd Colosio s/n entre Reforma y Sahuaripa, Hermosillo, Mexico, Email Itz@guaymas.uson.mx

Received: January 22, 2020 | Published: February 27, 2020

\section{Introduction}

One of the main concerns about the diverse activities related to food production is the environmental impact they can produce in the surrounding ecosystems. This is particularly true in the case of aquaculture, one of the most criticized productive activities because of its potential environmental impact. ${ }^{1}$ For shrimp aquaculture it was estimated that for each ton of biomass produced, around 1.6 tons of organic matter nitrogen and 0.8 tons of nitrogen are discharged in the effluents with the consequent adverse effects, and similar scenarios could be expected for fish aquaculture.

Tilapia is the second most farmed group of fish around the world with annual productions over five million tons, being the Nile tilapia, Oreochromis niloticus, the most cultured (FAO, 2018). Similarly, in México tilapia is the most farmed fish. These huge volume of production have negative impacts on the environment. ${ }^{2}$

Some strategies have been implemented to reduce the impact of aquaculture in the effluent-receiving ecosystems. In the case of tilapia and some other fish, one of the most efficient strategies is the reduction of the protein content of aquafeeds, reducing in this way the ammonia excretion and consequently it level in the effluents. ${ }^{3}$ Another environmentally friendly practice is the substitution of formulated feed by natural feed, including microorganisms immobilized in submerged fix (biofilms) or floating (bioflocs) substrates. Also, the recirculation systems and the utilization or reuse of effluents have demonstrated to be adequate and effective strategies for reducing the nutrients and organic matter destined to be discharged in the environment.

Aquaponics is a relatively novel production system which combine aquaculture and hydroponics to optimize the use of the nutrients and diminish their losses. ${ }^{4}$ The idea is to use the nutrients discarded by aquaculture (organisms excretions, molts, unconsumed feed, feces, etc.) for the growth of diverse plants, mainly those with a great demand and good market price in order to maximize the incomes of the production system. ${ }^{5}$ The plants must be selected based on the environmental conditions of the site, the concentration of nutrients in the aquaculture effluents, and their demand and price in the market, ${ }^{6}$ herein, several conventional greenhouse plants (cucumber, tomato, pepper, lettuce, etc.), herbs, medicinal plants, and nutraceutical plants, could be produced. ${ }^{7}$ Many reports around the world have documented the success of aquaponics using diverse species of fish, crustaceans and plants. Rakocy et al. ${ }^{8}$ successfully cultured tilapia and basil in an aquaponics system, while Nuwansi et al., ${ }^{1}$ reported good production of koi carp (Cyprinus carpio), goldfish (Carassius auratus) and water spinach (Ipomea aquatica) in a recirculating aquaponics system. Also, Ortega and Iváa evaluated the efficiency of aquaponics, culturing the sweet basil (Osimum basilicum) and the giant prawn (Macrobranchium rosenbergii), concluding that the polyculture is feasible, and it also improves the quality of pond water by absorption of nitrogen metabolites by the plants.

Additional steps could be integrated to the system for a greater optimization of nutrients by using the final effluent from aquaponics to fertigation of another plant. In this regard, peppers are vegetables widely consumed worldwide; these can be used as a spice or as ingredient for many meals, being among the vegetable substances used for seasoning or flavoring food, stimulating the appetite for the increasing the flow of gastric juice. ${ }^{10}$ Peppers have been used for antioxidant nutritive therapy and for treating cardio-vascular diseases, diabetes, erectile dysfunction, and respiratory diseases. ${ }^{10}$

The jalapeño pepper is widely consumed around the world, and is one of the most accepted by consumers in the United States due to its good flavor and low price Lilly white, while the bell pepper is less consumed and has a high price mainly during out-season. Therefore, this study was focused on preliminarily evaluate the feasibility of an integrated system to produce tilapia (aquaculture), jalapeño pepper (hydroponics), and mini bell pepper (soil fertigation), with and without using bioflocs for the cultured tilapia. 


\section{Materials and methods}

The study was conducted during eight weeks (mid-September to mid-November) in the facilities of the Departamento de Agricultura y Ganadería, Universidad de Sonora at Hermosillo, Sonora, México. It was done into a greenhouse used for agriculture and hydroponics of diverse plants, mainly peppers. The system consisted of three phases: 1) Aquaculture phase, using six plastic tanks $(500 \mathrm{~L}$ in capacity and managed at 400L) for the culture of tilapia; 2) Hydroponics phase, consisting of six PVC tubes (4" diameter and 6m length) with perforations each $40 \mathrm{~cm}$ to fit the jalapeño peppers using sponge strips; 3 ) Soil fertigation phase, consisting of six soil grooves for the culture of mini bell peppers.

For culturing tilapia each plastic tank was stocked with 30 $\left(75 / \mathrm{m}^{3} ; 2.1 \pm 0.9 \mathrm{~g}\right)$ fry of $O$. niloticus, donated by the Institute of Aquaculture of the State of Sonora (IAES). Constant aeration was applied to maintain dissolved oxygen levels over $5 \mathrm{mg} / \mathrm{L}$. Water quality parameters (temperature, $\mathrm{DO}$, and $\mathrm{pH}$ ) were monitored every day at 10:00 $\mathrm{h}$ using a multiparameter YSI sonde. Total ammonia concentration was measured weekly by spectrophotometry, using a Hanna programmable equipment and the kits provided by the manufacturer. Tilapia were fed at satiation with a commercial (Ziegler) diet containing $30 \%$ crude protein. Three of the tanks were additionally supplied with bioflocs produced in a single bioreactor, consisting of a plastic tank $(300 \mathrm{~L})$ provided with clean freshwater and constant aeration by means a blower through porous tubing. An inoculum of the microalgae Scenedesmus sp. was introduced at the beginning of the trial. The bioreactor was fertilized with Triple 17 $(17 \% \mathrm{~N}, 17 \% \mathrm{P}$, and $17 \% \mathrm{~K})$ when necessary, to maintain levels of phosphorous over $1 \mathrm{mg} / \mathrm{L}$. Wheat brand $(100 \mathrm{~g})$ and amaranth seeds

Table I Ranges of the water quality variables during the trial (100g) were supplied as nucleation substrates at the beginning of the study and when was necessary to maintain levels of total suspended solids around $20 \mathrm{~mL} / \mathrm{L}$ (measured by Imhoff cones).

The jalapeño pepper plants $(15 \mathrm{~cm}$ tall) were obtained by donation (Agroquimicos Jam S.A de C.V, Hermosillo, Sonora, Mexico). These were fixed to the hydroponics tubes one week after the tilapia stocking. The Mini bell pepper plants $(12 \mathrm{~cm}$ tall) were obtained from the same enterprise. These were planted in the soil grooves at the same time than jalapeños.

Every three days the water from the hydroponics tubes was verted to the grooves, and then replaced with water from the tilapia tanks. Three of the fish tanks were refilled with clean freshwater and three other with water from the biofloc reactor.

Tilapia were monitored weekly to measure weight (digital Ohaus balance), size (ichtiometer $\pm 1 \mathrm{~mm}$ ), and estimate survival. At the end of the trial, all fish were weighed, sized, and counted to know the final growth, survival, biomass, and feed conversion ratio.

The jalapeño and mini bell peppers were also monitored continuously to detect floriation time, plant growth, and number of fruits. At the end of the trial, all fruits were harvested, counted, and weighed.

\section{Results and discussion}

The water quality parameters in the aquaculture tanks were most of the time within the range recommended for the culture of the species (Table 1). However, the TAN registered values out of the recommended range for tilapia ${ }^{11}$ but no massive mortalities were observed in the tanks.

\begin{tabular}{llllll}
\hline & Temperature $\left({ }^{\circ} \mathbf{C}\right)$ & Salinity (UPS) & Oxygen $(\mathbf{m g} / \mathbf{L}$ & $\mathbf{p H}$ & Ammonia (mg/L) \\
\hline With Biofloc & 14.3 to 33.2 & 0.2 to 0.4 & 5.4 to 8.3 & 7.9 to 9.3 & 2.3 to 6.7 \\
Without Bioflocs & 14.2 to 33.3 & 0.2 to 0.4 & 5.6 to 8.5 & 7.8 to 9.9 & 1.9 to 5.7 \\
\hline
\end{tabular}

Most of the production parameters of tilapia recorded values into the range considered suitable for this type of culture (Table 2). Weight gain was grater in the tanks supplied with bioflocs $(120.3 \pm 26.3 \mathrm{~g})$ when compared to the tanks without bioflocs $(89.7 \pm 19.6 \mathrm{~g})$; however, the differences were not significant. Survival was similar between the two conditions $(82.6 \pm 2.3 \%$ and $80.4 \pm 1.9 \%$ for tanks with and

Table 2 Means $( \pm S D)$ of the production parameters of tilapia without bioflocs, respectively). The final biomass was significantly greater in the treatment using bioflocs $(2960 \pm 182 \mathrm{~g} / \mathrm{tank})$ as compared with that using formulated feed only $(2160 \pm 103 \mathrm{~g} / \mathrm{tank})$. The feed conversion ratio was also better (lower) for tilapia reared with bioflocs $(1.1 \pm 0.1 \mathrm{vs} 1.4 \pm 0.1)$. These results are not surprising considering that the presence of biofloc represents an additional and high-nutritional value food source for tilapia. ${ }^{13}$

\begin{tabular}{lllll}
\hline & Weight gain (g/fish) & Survival $(\%)$ & Biomass $(g /$ tank) & FCR \\
\hline With Bioflocs & $120.3 \pm 26.3 \mathrm{a}$ & $82.6 \pm 2.3 \mathrm{a}$ & $2969 \pm 182 \mathrm{~b}$ & $1.1 \pm 0.1 \mathrm{a}$ \\
Without Bioflocs & $89.7 \pm 19.6 \mathrm{a}$ & $80.4 \pm 1.9 \mathrm{a}$ & $2160 \pm 103 \mathrm{a}$ & $1.4 \pm 0.1 \mathrm{~b}$ \\
\hline
\end{tabular}

The jalapeño pepper did not have a good performance in the hydroponics system (Table 3). The mean survival was $63.5 \pm 4.6 \%$ in the tubes filled with water of tanks with bioflocs and $66.6 \pm 7.3 \%$ in those without; no significant differences were recorded among the two conditions. The growth (height) of the plants were similar, registering $26.4 \pm 2.4$ and $27.1 \pm 2.0 \mathrm{~cm}$ for plants cultured with the water of tilapia tanks with and without bioflocs, respectively. The floriation in all the units began 16 days after planting, and the fruits were detected six days later. The number of fruits per plants ranged from 1 to 3 and the biomass from $22.2 \pm 2.1$ to $23.3 \pm 3.6 \mathrm{~g} / \mathrm{plant}$, in the two conditions, without significant differences among them. These production parameters are very poor when compared to those reported in other studies with peppers in similar systems. ${ }^{14}$ This was probably related to adaptation problems of the plant to the hydroponics conditions 
(nutrients concentrations, flows, aeration, lack of substrate, and etcetera). It has been suggested that some peppers need to be amended with substrates to develop better under soilless farming. Graber et al., ${ }^{11}$ reported that pepper plant development in biochar-treated pots was significantly enhanced compared with the unamended controls, in terms of leaf area, canopy dry weight, number of nodes, and yields of buds, flowers, and fruit.

Table 3 Means $( \pm S D)$ of the production parameters of jalapeño pepper

\begin{tabular}{lllllll}
\hline & Height (cm) & Survival (\%) & Floriation (DAP) & Fructification (DAP) & $\begin{array}{l}\text { Fruits per } \\
\text { plant }\end{array}$ & $\begin{array}{l}\text { Biomass (g per } \\
\text { plant) }\end{array}$ \\
\hline With Bioflocs & $26.4 \pm 2.4 \mathrm{a}$ & $63.5 \pm 4.6 \mathrm{a}$ & $16 \pm \mathrm{la}$ & $22 \pm \mathrm{la}$ & $1.6 \pm 0.3 \mathrm{a}$ & $22.2 \pm 2.1 \mathrm{a}$ \\
Without Bioflocs & $27.1 \pm 2.0 \mathrm{a}$ & $66.6 \pm 7.3 \mathrm{a}$ & $16 \pm \mathrm{la}$ & $22 \pm \mathrm{la}$ & $1.7 \pm 0.3 \mathrm{a}$ & $23.3 \pm 3.6 \mathrm{a}$ \\
\hline
\end{tabular}

DAP $=$ Days after planting

The mini bell peppers had a relatively good performance in the soil fertigation conditions (Table 4). No significant differences in production parameters were found among units irrigated with water from hydroponics using biofloc or not in the tilapia culture. Growth $(38.8 \pm 4.3 \mathrm{~cm}$ vs $39.7 \pm 5.1 \mathrm{~cm})$, survival $(93.3 \pm 3.3 \%$ vs $100 \pm 0.0)$,

Table 4 Means $( \pm S D)$ of the production parameters of mini bell pepper floriation time (12 days after plantation for both conditions), time of appearance of fruits (18 days for both), number of fruits per plant (12.4 \pm 2.4 vs $12.9 \pm 2.6)$, and biomass of fruits per plant $(138.6 \pm 12.4 \mathrm{~g}$ vs $151.1 \pm 16.3 \mathrm{~g}$ ) resulted to be similar among treatments.

\begin{tabular}{lcccccc}
\hline & Height $(\mathbf{c m})$ & Survival (\%) & Floriation (DAP) & Fructification (DAP) & $\begin{array}{l}\text { Fruits per } \\
\text { plant }\end{array}$ & $\begin{array}{l}\text { Biomass (g per } \\
\text { plant) }\end{array}$ \\
\hline With Bioflocs & $38.8 \pm 4.3 \mathrm{a}$ & $93.3 \pm 3.3 \mathrm{a}$ & $12 \pm \mathrm{la}$ & $18 \pm \mathrm{la}$ & $12.4 \pm 2.4 \mathrm{a}$ & $138.6 \pm 12.4 \mathrm{a}$ \\
Without Bioflocs & $39.7 \pm 5.1 \mathrm{a}$ & $100 \pm 0.0 \mathrm{~b}$ & $12 \pm \mathrm{la}$ & $18 \pm \mathrm{la}$ & $12.9 \pm 2.6 \mathrm{a}$ & $151.1 \pm 16.3 \mathrm{a}$ \\
\hline
\end{tabular}

$\mathrm{DAP}=$ Days after planting

Therefore, the jalapeño pepper resulted not to be an adequate candidate for hydroponics under the conditions established in this trial; however, the mini bell pepper could be produced in these kinds of systems including those using bioflocs, contributing to the reuse of effluents. I this regard, Palada et al. ${ }^{15}$ demonstrated the positive benefits of using aquaculture effluents (tank water and sludge) in pepper production. Developing techniques for water conservation and reuse is relevant for the aqua- and agri-business in arid and semi-arid regions, and in this sense the irrigation with nutrient-rich aquaculture effluents sounds being an adequate management technique. ${ }^{16,17}$

The results of this preliminary study suggest that the multiphasic integrated system could be efficient for the culture of tilapia and pepper; however, further research is required in terms of adjustment of nutrients and flow of the effluents from tilapia culture, as well as the selection of the best vegetable species for the hydroponics conditions. Moreover exploring the possibility of substrates for the hydroponics phase and selection of the best period of the year for the production should be considered.

\section{Acknowledgments}

None.

\section{Funding}

None.

\section{Conflicts of interest}

The author declares that there are no conflicts of interest.

\section{References}

1. Nuwansi KKT, Verma AK, Prakash C, et al. Effect of water flow rate on polyculture of koi carp (Cyprinus carpio var. koi) and goldfish (Carassius auratus) with water spinach (Ipomoea aquatica) in recirculating aquaponic system. Aquaculture international. 2016;24(1):385-393.

2. Baccarin AE, Camargo AFM. Characterization and evaluation of the impact of feed management on the effluents of Nile tilapia (Oreochromis niloticus) culture. Brazilian Archives of Biology and Technology. 2005;48(1):81-90.

3. Teodósio R, Engrola S, Colen R, et al. Optimizing diets to decrease environmental impact of Nile tilapia (Oreochromis niloticus) production. Aquaculture Nutrition. 2019.

4. Rakocy JE. Aquaponics: integrating fish and plant culture. Aquaculture production systems. 2012;1:343-386.

5. Love DC, Fry JP, Li X, et al. Commercial aquaponics production and profitability: Findings from an international survey. Aquaculture. 2015;435:67-74.

6. Blidariu F, Grozea A. Increasing the economical efficiency and sustainability of indoor fish farming by means of aquaponics-review. Scientific Papers Animal Science and Biotechnologies. 2011;44(2):1-8.

7. Savidov NA, Hutchings E, Rakocy JE. Fish and plant production in a recirculating aquaponic system: a new approach to sustainable agriculture in Canada. In International Conference and Exhibition on Soilless Culture: ICESC 2005. 2005;(pp. 209-221).

8. Rakocy J, Shultz RC, Bailey DS, et al. Aquaponic production of tilapia and basil: comparing a batch and staggered cropping system. In South Pacific Soilless Culture Conference-SPSCC. 2003; 648:63-69. 
9. Ortega MR, Iva C. Hydroponic and aquaponic production of sweet basi (Ocimum basilicum) and giant river prawn (Macrobrachium rosenbergii). Tropical and Subtropical Agroecosystems. 2012;15(S2).

10. Ilodibia CV, Ugwuoke CE, Egboka TP, et al. Breeding pepper for enhanced food nutrients. Asian Journal of Crop Science. 2015; 7(3):214-218.

11. Graber ER, Harel YM, Kolton M, et al. Biochar impact on development and productivity of pepper and tomato grown in fertigated soilless media Plant and soil. 2010;337(1-2):481-496.

12. Benli AÇK, Köksal G, Özkul A. Sublethal ammonia exposure of Nile tilapia (Oreochromis niloticus L.): effects on gill, liver and kidney histology. Chemosphere. 2008;72(9):1355-1358.

13. Ekasari J, Rivandi DR, Firdausi AP, et al. Biofloc technology positively affects Nile tilapia (Oreochromis niloticus) larvae performance Aquaculture. 2015;441:72-77.
14. Harjoko D, Utami RS, Arniputri RB. Hydroponic of Chili with substrates variation. In IOP Conference Series: Earth and Environmental Science. IOP Science. 2018; 200(1):012016.

15. Palada MC, Cole WM, Crossman SM. Influence of effluents from intensive aquaculture and sludge on growth and yield of bell peppers. Journal of Sustainable Agriculture. 1999;14(4):85-103.

16. Asase A, Nunoo FKE, Attipoe FYK. Lake-Based Nursery Rearing of Nile Tilapia (Oreochromis niloticus) Fingerlings in Nylon Hapas: Effects of Stocking Density on Growth, Survival and Profitability. Agricultural Sciences. 2016;7(10):660-669.

17. Shnel N, Barak Y, Ezer T, et al. Design and performance of a zerodischarge tilapia recirculating system. Aquacultural Engineering. 2002;26(3):191-203. 